\title{
Modulation of human T-lymphocyte functions by the consumption of carotenoid-rich vegetables
}

\author{
Bernhard Watzl $^{1 *}$, Achim Bub ${ }^{1}$, Birgit R. Brandstetter ${ }^{2}$ and Gerhard Rechkemmer ${ }^{1}$ \\ ${ }^{1}$ Institute of Nutritional Physiology, Federal Research Centre for Nutrition, Haid-und-Neu-Str. 9, 76131 Karlsruhe, Germany \\ ${ }^{2}$ Department of Epidemiology, German Cancer Research Centre, Im Neuenheimer Feld 280, 69120 Heidelberg, Germany
}

(Received 8 June 1998 - Revised 17 May 1999 - Accepted 31 May 1999)

\begin{abstract}
A human intervention study was conducted to determine the effect of the consumption of carotenoid-rich vegetables on the immune system. Subjects, (twenty-three men), who were nonsmokers, were not restricted in their daily diet, except that they had to abstain from fruit and vegetables high in carotenoids throughout the whole study period. The study was divided into four periods, each lasting 2 weeks: weeks 1-2: low-carotenoid period; throughout weeks 3-8: daily consumption of $330 \mathrm{ml}$ tomato juice ( $40 \mathrm{mg}$ lycopene $/ \mathrm{d}, 1.5 \mathrm{mg} \beta$-carotene/d) (weeks 3-4), $330 \mathrm{ml}$ carrot juice $(21.6 \mathrm{mg} \beta$-carotene $/ \mathrm{d}, 15.7 \mathrm{mg} \alpha$-carotene $/ \mathrm{d}, 0.5 \mathrm{mg}$ lutein/d) (weeks 5-6), $10 \mathrm{~g}$ dried spinach powder $(11.3 \mathrm{mg}$ lutein $/ \mathrm{d}, 3.1 \mathrm{mg} \beta$-carotene/d) (weeks $7-8$ ). Blood was collected weekly from subjects after a $12 \mathrm{~h}$ fast. T-lymphocyte functions were assessed by measuring proliferation and secretion of immunoreactive cytokines. The consumption of a lowcarotenoid diet resulted in a significantly reduced proliferation of peripheral blood mononuclear cells (PBMC) cultured with concanavalin A. After 2 weeks of tomato juice consumption and until the end of the intervention period lymphocyte proliferation was not significantly changed compared with proliferation at the end of the depletion period. Secretion of cytokines by T-helper-1-like lymphocytes (interleukin (IL)-2) and by T-helper-2-like lymphocytes (IL-4) was influenced by the dietary intervention. IL-2 and IL-4 secretion values were significantly suppressed after the low-carotenoid diet $(P<0.001$ and $P<0.05$ respectively compared with baseline). Tomato juice consumption significantly enhanced IL-2 $(P<0.001)$ and IL-4 secretion $(P<0.05)$ compared with the end of depletion period. After carrot juice and spinach powder consumption the cytokine secretion capacity of PBMC was not significantly different from that at the end of the depletion period. In conclusion, the results of the present study indicate that a lowcarotenoid diet reduces T-lymphocyte functions and addition of tomato juice restores these functions. This modulation could not be explained by changes in the plasma carotenoid concentrations. The active constituents in tomato juice as well as the biological significance of this immunomodulation remain to be determined.
\end{abstract}

Carotenoids: Vegetable consumption: T-lymphocytes: Cytokines

Carotenoids are common constituents in many vegetable and fruit varieties (Mangels et al. 1993). Only for $\beta$-carotene, with its provitamin A activity, have the biological activities of carotenoids been intensively studied (Burri, 1997). With the results of the Alpha-Tocopherol BetaCarotene (ATBC) and Carotenoid Retinol (CARET) studies (The Alpha-Tocopherol, Beta-Carotene Cancer Prevention Study Group, 1994; Omenn et al. 1996), however, interest has increased in the physiological effects of carotenoids other than $\beta$-carotene. Recently, lycopene and oxocarotenoids (xanthophylls) have become a major focus in carotenoid research (Stahl \& Sies, 1996; Bone et al. 1997; Gerster, 1997).
The immunomodulatory activity of $\beta$-carotene has been thoroughly investigated in several animal species and in a number of human trials (Bendich, 1989; Watson et al. 1991; Meydani et al. 1995a). While the animal studies have shown an immunoenhancing effect of pure $\beta$-carotene (Bendich, 1991), results from human trials are inconsistent. Studies have reported stimulation of various immune functions with $\beta$-carotene supplementation (Meydani et al. 1995b; Moriguchi et al. 1996; Santos et al. 1996; Hughes et al. 1997a,b; Kazi et al. 1997) or have observed no effects (Meydani et al. 1995b; Kramer \& Burri, 1997). Most human studies have used pure $\beta$-carotene in dosages ranging from 15 to $300 \mathrm{mg} / \mathrm{d}$ for short- and long-term periods (Meydani et al. 1995b).

\footnotetext{
Abbreviations: ABTS, 2,2'-azino-bis-3-ethylbenzothiazoline-6-sulfonic acid; ConA, concanavalin A; IL, interleukin; PBMC, peripheral blood mononuclear cells.

* Corresponding author: Dr Bernhard Watzl, fax +49 7216625 404, email bernhard.watzl@bfe.uni-karlsruhe.de
} 
Depletion studies with low- $\beta$-carotene diets have revealed conflicting results. Daudu et al. (1994) reported no effect on lymphocyte proliferation of a low- $\beta$-carotene diet consumed for $68 \mathrm{~d}$, while Kramer \& Burri (1997) observed a suppressed proliferative responsiveness of lymphocytes in human subjects consuming a low- $\beta$-carotene diet $(0.5 \mathrm{mg} / \mathrm{d})$ for $60 \mathrm{~d}$. These controversial results may be due to methodological differences in the protocol of peripheral blood mononuclear cell (PBMC) isolation.

Besides $\beta$-carotene only lycopene has been studied in human subjects. Supplementation with $15 \mathrm{mg}$ lycopene/d for $28 \mathrm{~d}$ induced no consistent changes in monocyte surface marker expression (Hughes et al. 1997b). The immunomodulatory activity of other carotenoids in human subjects is not known. There is one study which investigated the effects of consuming carotenoid-rich vegetable extracts on lymphocyte functions (T-lymphocyte proliferation) in human subjects (Clevidence et al. 1997). In this study a carotenoid complex from vegetables was consumed, which provided $\beta$-carotene $(3.3 \mathrm{mg} / \mathrm{d})$, lycopene $(0.6 \mathrm{mg} / \mathrm{d})$ and lutein/zeaxanthin $(1.5 \mathrm{mg} / \mathrm{d})$. Lymphocyte proliferation was enhanced after the consumption of the carotenoid complex. So far, no study has investigated the effects of consuming carotenoidrich vegetables on the human immune system.

The objective of the present study was to examine the effects of consuming different carotenoid-rich vegetable products on T-lymphocyte functions in healthy adult male subjects. Carotenoids ( $\alpha$-carotene, $\beta$-carotene, lycopene, lutein) were provided by highly accessible food matrices (processed vegetable products) in amounts possibly consumed by people eating a Mediterranean-type diet. In a preliminary study we showed that for processed carotenoidrich vegetables a supplementation period of 2 weeks was sufficient to increase plasma carotenoid concentrations 2-3fold ( $\mathrm{H}$ Müller, A Bub, B Watzl and G Rechkemmer, unpublished results). In the present study, after a carotenoid depletion period of 2 weeks the low-carotenoid diet of the subjects was supplemented daily for 2 weeks with tomato juice (lycopene) followed by carrot juice ( $\alpha$-carotene, $\beta$-carotene) and by spinach powder (lutein). No wash-out periods between the different supplementation periods were used in order to mimic more closely the dietary behaviour of consumers. Plasma concentrations of major carotenoids (including trans- and cis-isomers and epoxides), $\alpha$ - and $\gamma$ tocopherols, retinol, and ascorbic acid were measured (Müller et al. 1999). T-lymphocyte functions were assessed by measuring mitogen-activated proliferation. In order to detect whether T-lymphocytes were affected as a total cell population or whether subgroups of T-lymphocytes were differentially affected, the secretion of T-helper-1 lymphocyte specific (interleukin (IL)-2) and T-helper-2 lymphocyte specific (IL-4) cytokines was quantitated.

\section{Subjects and methods}

\section{Subjects}

Twenty-three non-smoking men (aged 27-40 years), with normal weight (BMI $23 \cdot 1($ SD 0.39$) \mathrm{kg} / \mathrm{m}^{2}$ ) were recruited for the study. All subjects were in good medical health as determined by a screening history and medical examination.
None was taking vitamin supplements or medications from 1 month before or during the study. The study was approved by the Medical Ethical Committee of the Landesärztekammer Baden-Württemberg and all participants gave their consent in writing. All participants were employees from the Research Centre Karlsruhe, where the Institute of Nutritional Physiology of the Federal Research Centre for Nutrition is located.

\section{Study design}

This study was conducted during the months of October to December. The study was divided into four periods each lasting 2 weeks, resulting in a total study period of 8 weeks: weeks 1-2 low-carotenoid period, weeks 3-4 tomato juice consumption $(330 \mathrm{ml} / \mathrm{d}$ providing $40 \mathrm{mg}$ lycopene and $1.5 \mathrm{mg} \beta$-carotene; Schoenenberger, Magstadt, Germany), weeks $5-6$ carrot juice consumption $(330 \mathrm{ml} / \mathrm{d}$ providing $21.6 \mathrm{mg} \beta$-carotene, $15.7 \mathrm{mg} \alpha$-carotene and $0.5 \mathrm{mg}$ lutein; Schoenenberger), weeks $7-8$ spinach powder consumption $(10 \mathrm{~g} / \mathrm{d}$ providing $11.3 \mathrm{mg}$ lutein and $3.1 \mathrm{mg} \beta$-carotene; Völpel, Königsmoos, Germany). In order to supply a standardized quantity of carotenoids through the vegetables, we used vegetable juices. Since there was no juice from green, lutein-rich vegetables available on the German market, we decided to use spinach powder, which was dissolved by the study subjects in water, milk, yoghurt or soup. Subjects were told to consume the vegetable products with their main meals. Subjects were not restricted in their daily diet except that they had to abstain from fruit and vegetables high in carotenoids throughout the whole study period. A list of the fruit and vegetables the subjects were not allowed to eat was provided (Müller et al. 1999). Subjects had to record their daily fruit and vegetable consumption throughout the whole study period. The daily carotenoid intake provided by fruit and vegetables was quantified by using a dietary assessment software package (PRODI 4.4, Nutri-Science, Karlsruhe, Germany), which is based on the German Food Code and Nutrition Data Base (Bundesinstitut für gesundheitlichen Verbraucherschutz und Veterinärmedizin, 1994). Total carotenoid and ascorbic acid intakes of the study subjects before the study period were assessed using a validated food-frequency questionnaire (Boeing et al. 1997).

\section{Preparation of peripheral blood mononuclear cells}

Blood from fasting subjects was collected once weekly between 07.00 and 09.00 hours; plasma was separated and an equal amount of PBS was added. PBMC were isolated by density-gradient centrifugation using Histopaque 1077 (Sigma, Deisenhofen, Germany) and were washed twice with PBS. Purified PBMC were resuspended in complete RPMI-1640 culture medium (Life Sciences, Eggenstein-Leopoldshafen, Germany), containing $50 \mathrm{ml}$ fetal bovine serum/l (Life Sciences), L-glutamine $(2 \mathrm{mmol} / \mathrm{l})$, penicillin $(100000 \mathrm{U} / \mathrm{l})$ and streptomycin $(100 \mathrm{mg} / \mathrm{l})$. Trypan blue staining was used to assess cell viability, and lymphocytes were counted in a haemocytometer under a light microscope. 


\section{Leucocyte numbers}

Total leucocyte numbers were determined on fasting blood after each week. Leucocyte numbers were obtained by using an automated analyser (F-300, Sysmex, Hamburg, Germany) according to standard operational procedures.

\section{Lymphocyte proliferation}

PBMC from each subject at $1 \times 10^{9}$ cells $/ 1$ in complete RPMI-1640 medium were cultivated in quadruplicate in flat-bottomed ninety-six-well microtitre plates (Greiner, Nürtingen, Germany) and stimulated by the T-cell mitogen concanavalin A (ConA; $5 \mathrm{mg} / \mathrm{l}$; Sigma) for $120 \mathrm{~h}$ at $37^{\circ}$ in an atmosphere of $50 \mathrm{ml} \mathrm{CO}_{2} / 1$ and $95 \%$ humidity. PBMC were pulse-labelled with the thymidine analogue 5-bromo-deoxyuridine (100 $\mu \mathrm{mol} / \mathrm{l}$; Boehringer, Mannheim, Germany) for $3 \mathrm{~h}$ at $37^{\circ}$. The incorporated 5-bromodeoxyuridine was detected by a quantitative cellular enzyme immunoassay using a commercial ELISA kit (Boehringer), following the manufacturer's instructions. The amount of incorporated 5-bromo-deoxyuridine is quantified by measuring the absorbance of the samples in a multiplate spectrophotometer (Molecular Devices, Menlo Park, CA, USA) at $450 \mathrm{~nm}$ (reference wavelength $650 \mathrm{~nm}$ ). As background control absorbance was measured in wells which were not pulse-labelled with 5-bromodeoxyuridine. Proliferative responses were expressed as the net absorbance values (absorbance $\mathrm{A}_{\mathrm{A} 50 \mathrm{~nm}-\mathrm{A} 650 \mathrm{~nm}}$ of pulselabelled cells - absorbance ${ }_{\mathrm{A} 450 \mathrm{~nm}-\mathrm{A} 650 \mathrm{~nm}}$ of unlabelled cells).

\section{Interleukin-2 and interleukin-4}

PBMC from each subject at $1 \times 10^{9}$ cells/l in complete RPMI-1640 medium were stimulated in quadriplicate by $5 \mathrm{mg}$ ConA/l for $48 \mathrm{~h}$ at $37^{\circ}$. Microplates were centrifuged for $5 \mathrm{~min}$ at $300 \mathrm{~g}$ and cell-free supernatant fractions were collected and stored at $-80^{\circ}$ until analysis. IL-2 and IL-4 were quantified by ELISA methods. For IL-2, microtitre plates (Maxisorp, NUNC, Roskilde, Denmark) were coated with $50 \mu \mathrm{l}$ of an anti-human IL-2 monoclonal antibody ( $4 \mathrm{mg} / \mathrm{l}$ carbonate buffer, pH 9.6; R\&D Systems, Wiesbaden, Germany) and stored overnight at $4^{\circ}$. Between subsequent steps in the assay, plates were washed five times with PBS-Tween (0.01 M-PBS containing $0.5 \mathrm{ml}$ Tween 20/l) with an automated plate washer (Molecular Devices). Non-specific binding was blocked by adding $50 \mu$ l bovine serum albumin (10 ml/l in PBS-Tween; Boehringer) for $1 \mathrm{~h}$ at $37^{\circ}$. Plates were incubated with supernatant fractions and with serial dilutions of recombinant human IL-2 (R\&D Systems) diluted in complete RPMI-1640 medium. Then $50 \mu \mathrm{l}$ of a polyclonal goat anti-human IL-2 neutralizing antibody ( $8 \mathrm{mg} / \mathrm{l}$ PBS-Tween and $10 \mathrm{ml}$ bovine serum albu$\mathrm{min} / \mathrm{l}$; R\&D Systems) was added for $1 \mathrm{~h}$ at room temperature, followed by a further $1 \mathrm{~h}$ of incubation with $50 \mu \mathrm{l}$ of a rabbit anti-goat immunoglobulin $\mathrm{G}$ peroxidase-conjugated antibody (dilution 1:40000 in PBS-Tween and $10 \mathrm{ml}$ bovine serum albumin/l; Jackson ImmunoResearch Laboratories, Hamburg, Germany). As a peroxidase substrate, $100 \mu l$ of a 2,2'-azino-bis-3-ethylbenzothiazoline-6-sulfonic acid buffer (ABTS; Sigma) (0.54 g ABTS and $21 \mathrm{~g}$ citric acid monohydrate, in 1 litre water, $\mathrm{pH} 4 \cdot 2$, with final concentration of $0.3 \mathrm{ml} \mathrm{H} \mathrm{H}_{2} \mathrm{O}_{2} / \mathrm{l}$ ) was used. Optical density was measured with a multiplate spectrophotometer (Molecular Devices) at $405 \mathrm{~nm}$.

IL-4 was measured in a similar way to IL-2 with the following reagents. Coating: polyclonal anti-human IL-4 ( $0.5 \mathrm{mg} / \mathrm{l}$; Endogen, Cambridge, MA, USA); blocking: $40 \mathrm{ml}$ bovine serum albumin/l in PBS-Tween; standards: recombinant human IL-4 (Endogen); detecting antibody: biotin-labelled anti-human IL-4 monoclonal antibody $(0.25 \mathrm{mg} / \mathrm{l}$; Endogen); peroxidase-conjugated streptavidin (0.5 mg/l; Jackson ImmunoResearch Laboratories).

\section{Statistics}

The results for plasma carotenoids and leucocyte numbers are expressed as means and standard deviations and the results for the immunological measurements as means with their standard errors. Differences between values for week 2 (end of depletion) and supplementation with the vegetable products for 2 weeks within the same group were examined by Wilcoxon matched pairs signed rank test. Statistical significance was accepted at $P<0 \cdot 05$. All statistical calculations were performed with the Statistical Analysis Systems computer software program (SAS for Windows, version 6.12; SAS Institute, Cary, NC, USA).

\section{Results}

\section{Plasma carotenoids}

Compliance of the study subjects was high, with no subject missing the daily intake of the vegetable products. During the 2-week low-carotenoid period there was no statistically significant change in plasma carotenoids compared with prestudy plasma concentrations (Table 1). Tomato juice, carrot juice, and spinach powder consumption each resulted in a significant increase of the vegetable-specific carotenoids compared with plasma concentrations at the end of the depletion period (Table 1). The increase in lycopene concentration in week 4 was not associated with changes in other carotenoids (Müller et al. 1999). In week 6 plasma lycopene concentration returned to baseline concentration. Plasma retinol, $\alpha$-tocopherol and ascorbic acid concentrations did not change throughout the intervention period (Müller et al. 1999; A Bub, B Watzl, J Wever, SL Abrahamse, H Delincée, ST Adam, S Mittenzwei, J Hegele, H Müller and $G$ Rechkemmer, unpublished results). The average daily intake of total carotenoids from self-selected foods during the study period based on food records was 1.32 (SD 0.57 ) $\mathrm{mg}$, with $57 \%$ derived from $\beta$-carotene, $6 \%$ from $\alpha$-carotene, $36 \%$ from lutein and $2 \%$ from lycopene. Total carotenoid and ascorbic acid intakes before the study period were calculated to be 3.48 (SD 2.17) $\mathrm{mg} / \mathrm{d}$ and 114.3 (SD 48.9$) \mathrm{mg} / \mathrm{d}$ respectively.

\section{Leucocyte numbers}

Total leucocyte numbers were constant throughout the whole study period starting with $5.5 \times 10^{9}$ cells/l and ending with $5.2 \times 10^{9}$ cells $/ 1$ (range $5 \cdot 1-5.5 \times 10^{9}$ cells $/ 1$ ). 
Table 1. Plasma carotenoid concentrations $(\mu \mathrm{mol} / \mathrm{l})$ and proliferation and interleukin-4 production $(\mathrm{pg} / \mathrm{ml})$ by peripheral blood mononuclear cells of subjects consuming a low-carotenoid diet (weeks 0-2) supplemented with tomato juice (weeks 3-4), carrot juice (weeks 5-6) or spinach powder (weeks 7-8)†

(Mean values and standard deviations (plasma carotenoids) or standard errors (lymphocyte functions) for twenty-three subjects)

\begin{tabular}{|c|c|c|c|c|c|c|c|c|c|c|c|c|c|c|c|c|c|c|}
\hline \multirow{4}{*}{ Week... } & \multirow{2}{*}{\multicolumn{2}{|c|}{$\begin{array}{c}\text { Baseline } \\
0\end{array}$}} & \multicolumn{4}{|c|}{ Depletion } & \multicolumn{4}{|c|}{ Tomato juice } & \multicolumn{4}{|c|}{ Carrot juice } & \multicolumn{4}{|c|}{ Spinach powder } \\
\hline & & & \multicolumn{2}{|c|}{1} & \multicolumn{2}{|c|}{2} & \multicolumn{2}{|c|}{3} & \multicolumn{2}{|l|}{4} & \multicolumn{2}{|c|}{5} & \multicolumn{2}{|c|}{6} & \multicolumn{2}{|c|}{7} & \multicolumn{2}{|c|}{8} \\
\hline & & SD or & & & & SD or & & & & SD or & & & & SD or & & & & SD or \\
\hline & Mean & SE & Mean & SE & Mean & SE & Mean & SE & Mean & SE & Mean & SE & Mean & SE & Mean & SE & Mean & SE \\
\hline \multicolumn{19}{|l|}{ Plasmał } \\
\hline Lycopene & 0.16 & 0.07 & - & & 0.16 & 0.08 & - & & $0.38^{*}$ & 0.13 & - & & $0 \cdot 15$ & 0.05 & - & & 0.14 & 0.06 \\
\hline$\beta$-Carotene & 0.74 & 0.44 & - & & 0.60 & 0.36 & - & & 0.65 & 0.25 & - & & $2.05^{*}$ & 0.72 & - & & $1 \cdot 21^{*}$ & 0.51 \\
\hline Lutein & 0.37 & $0 \cdot 14$ & - & & 0.35 & 0.12 & - & & 0.33 & 0.12 & - & & 0.36 & 0.11 & - & & $0.71^{*}$ & 0.17 \\
\hline \multicolumn{19}{|l|}{ Lymphocyte } \\
\hline Proliferation§ & 1.57 & 0.06 & 1.61 & 0.08 & 1.47 & 0.08 & $1 \cdot 25^{*}$ & 0.05 & 1.52 & 0.07 & 1.60 & 0.06 & $1 \cdot 61$ & 0.06 & 1.53 & 0.06 & 1.31 & 0.06 \\
\hline Interleukin-4 & $35 \cdot 0^{*}$ & $5 \cdot 3$ & $29 \cdot 6$ & $14 \cdot 6$ & $27 \cdot 9$ & $3 \cdot 1$ & $26 \cdot 5$ & $16 \cdot 5$ & $36 \cdot 4^{*}$ & 4.0 & $33 \cdot 3^{*}$ & $4 \cdot 4$ & $30 \cdot 8$ & 3.0 & $32 \cdot 5$ & $4 \cdot 3$ & 26.9 & $3 \cdot 6$ \\
\hline
\end{tabular}

Mean values were significantly different from those for week $2:{ }^{*} P<0.05$

†For details of diets and procedures, see pp. 384-385.

$\ddagger$ Data are from Müller et al. (1999). Plasma carotenoids were not determined at weeks 1, 3, 5 and 7 .

$\S$ Measured as absorbance at $450 \mathrm{~nm}$ minus absorbance at $650 \mathrm{~nm}$.

\section{Lymphocyte functions}

In a dose-response curve with ConA, $5 \mathrm{mg}$ ConA/l gave the maximum proliferative responsiveness and maximum cytokine secretion. This concentration was, therefore, used throughout the study. Lymphocyte proliferation decreased at the end of the low-carotenoid period (week $1 v$. week 2, $P=0.07)$ and after the first week of tomato juice consumption proliferation was significantly suppressed compared with proliferation at the end of the depletion period (Table 1). After a further week of tomato juice consumption and until the end of the intervention period proliferation did not differ compared with proliferation at the end of the depletion period (Table 1).

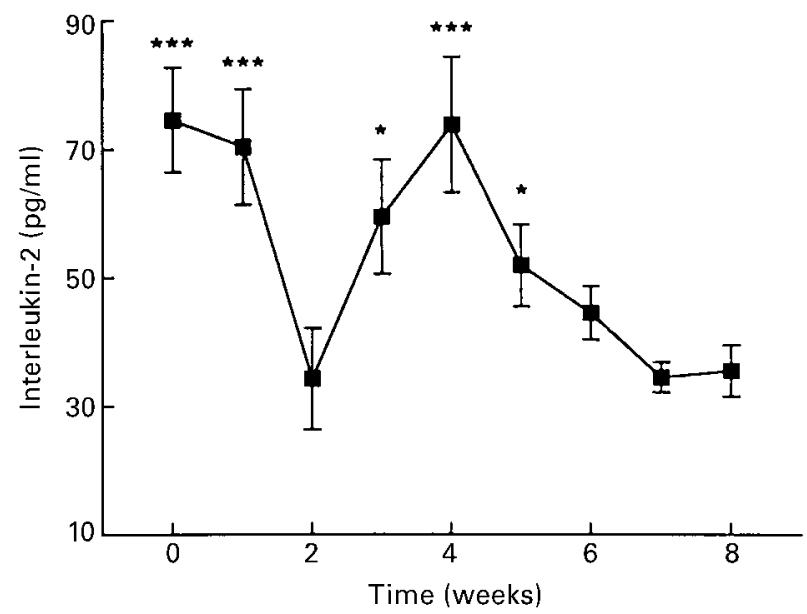

Fig. 1. Concentration of interleukin-2 $(\mathrm{pg} / \mathrm{ml})$ secreted by peripheral blood mononuclear cells (PBMC) activated with concanavalin $A$ $(5 \mathrm{mg} / \mathrm{l})$ and cultured for $48 \mathrm{~h}$ at $37^{\circ}$ and $50 \mathrm{ml} \mathrm{CO} / \mathrm{ll}$. PBMC were isolated from subjects ( $n$ 23) who consumed a low-carotenoid diet (weeks 0-2), which was supplemented with tomato juice (weeks $3-$ 4), carrot juice (weeks 5-6) or spinach powder (weeks 7-8). Values are means with their standard errors represented by vertical bars. Mean values were significantly different from those for week $2:{ }^{*} P<$ $0.05,{ }^{* * *} P<0.001$.
The concentrations of immunoreactive IL-2 secreted into the culture media by the PBMC from study subjects when cultured with ConA are shown in Fig. 1. There was a significant decline in the capacity to secrete IL-2 after 2 weeks of consuming the low-carotenoid diet. The supplementation with tomato juice activated PBMC to secrete IL-2 in an amount similar to the prestudy concentration. After the 2 weeks of carrot juice consumption and after two further weeks of spinach powder consumption no increased capacity to secrete IL-2 compared with week 2 was observed.

The capacity of PBMC to secrete immunoreactive IL-4 was also modulated by the dietary intervention. The low carotenoid intake during the first 2 weeks resulted in a significant reduction of IL-4 secretion (Table 1). Tomato juice consumption for 2 weeks increased IL-4 secretion capacity of PBMC significantly. Again, 2 weeks of carrot juice consumption and of spinach powder consumption did not result in an enhanced IL-4 secretion compared with the end of the depletion period.

\section{Discussion}

The immune system is a major component in the pathogenesis of several chronic diseases like cancer and cardiovascular disease. Epidemiological studies have consistently found that an inverse relationship between intake of vegetables and fruit and risk for these diseases exists (Steinmetz \& Potter, 1991; Block et al. 1992; Key et al. 1996; Ness \& Powles, 1997). The constituents in vegetables and fruit contributing to the preventive effects are not yet identified. In addition, a strong inverse association between dietary intake of $\beta$-carotene and cancer risk has been observed in several epidemiological studies (Mayne, 1996). Since dietary $\beta$-carotene is mostly provided by vegetables and fruit, the immunomodulatory activity of $\beta$-carotene may contribute to the observed protective effects of these food items.

Subjects enrolled in our present study had a total carotenoid intake of $3.48(\mathrm{SD} 2.17) \mathrm{mg} / \mathrm{d}$ before entering the study. Since the average carotenoid intake of males in 
Germany (aged $24-50$ years) is $5.6 \mathrm{mg} / \mathrm{d}$ (Pelz et al. 1998), our study subjects were consuming relatively low levels of fruit and vegetables. The results of our study show that the consumption of a diet low or high in carotenoid-rich vegetable products modulates T-lymphocyte functions as measured in in vitro assays. A low intake of carotenoid-rich vegetables decreased lymphocyte proliferation and inhibited the capacity to secrete cytokines, although plasma carotenoid concentrations were not reduced significantly during this period. Supplementing the low-carotenoid diet with vegetable products high in specific carotenoids significantly increased plasma concentrations of these carotenoids. However, only after the tomato juice period were T-lymphocyte functions enhanced compared with the end of the depletion period. This enhancement was paralleled by a significant increase in plasma lycopene concentration (Müller et al. 1999).

The reduced lymphocyte proliferative responsiveness observed after 1 week of tomato juice consumption may have been a consequence of the preceeding low-carotenoid period and not an effect of the tomato juice consumption. The different kinetics of the dietary intervention on T-lymphocyte proliferation and IL-2 secretion suggests that IL-2 secretion capacity is more sensitive to such dietary treatments than T-lymphocyte proliferation. Reduction of IL-2 secretion in week 2 preceded the lowered lymphocyte proliferation in week 3 and the recovery in IL-2 secretion in week 3 preceded the recovery in lymphocyte proliferation.

After carrot juice and spinach powder consumption, T-lymphocyte functions were not significantly different compared with week 2 (end of depletion). While at the end of week 6 plasma lycopene concentration had returned to the prestudy concentration, $\alpha$ - and $\beta$-carotene and lutein concentrations were increased compared with week 2 . These results suggest that tomato juice consumption, as indicated by the high plasma lycopene concentration, is related to the increased cytokine secretion capacity observed after week 4, and tomato juice-specific ingredients may be necessary for adequate T-lymphocyte functions.

Other studies have also investigated the impact of lowcarotenoid diets on lymphocyte functions. Consumption of a low-carotenoid diet $(\beta$-carotene $<0.1 \mathrm{mg} / \mathrm{d}$ or $=0.5 \mathrm{mg} / \mathrm{d})$ for $60 \mathrm{~d}$ significantly suppressed lymphocyte proliferation without significantly changing plasma $\beta$-carotene concentrations (Kramer \& Burri, 1997), which helps to confirm the results of the present study. The uptake of a carotenoid complex from vegetables for $20 \mathrm{~d}$ corrected the proliferative response (Kramer \& Burri, 1997). These results suggest that a $\beta$-carotene dosage of $0.5 \mathrm{mg} / \mathrm{d}$ may be too low to allow normal proliferation or that the uptake of a mixture of several carotenoids is required in order for lymphocytes to function properly. The results of both studies also question the significance of plasma $\beta$-carotene concentrations during $\beta$-carotene depletion periods as a factor influencing lymphocyte functions. Probably PBMC carotenoid concentrations more closely mirror the effect of low-carotenoid diets as has been suggested by others recently (Fotouhi et al. 1996). In addition, non-carotenoid constituents in carotenoid-rich vegetables could also modulate T-lymphocyte functions. A similar study design was used in another investigation in which $\beta$-carotene depletion as well as repletion with pure $\beta$-carotene $(15 \mathrm{mg} / \mathrm{d})$ did not influence lymphocyte proliferation (Daudu et al. 1994). In this study plasma $\beta$-carotene concentration significantly decreased during depletion.

In several studies supplementation with $\beta$-carotene without using a depletion period before supplementation did not affect lymphocyte proliferation (Ringer et al. 1991; Meydani et al. 1995a). In a study on nutrition and lymphocyte proliferation in young and aged subjects plasma $\beta$-carotene concentration also did not correlate with lymphocyte proliferative responsiveness (Gardner et al. 1997). Only one study has clearly demonstrated a stimulatory effect on lymphocyte proliferation after supplementation with $30 \mathrm{mg} \beta$-carotene/d for $28 \mathrm{~d}$ (Moriguchi et al. 1996). Besides $\beta$-carotene there is no in vivo study on lycopene and lymphocyte proliferation and only one study which has investigated the effect of lutein on lymphocyte proliferation. In this animal study a lutein-rich extract from marigold (Tagetes patula) was applied orally for 2 and 4 weeks. This treatment resulted in an enhanced lymphocyte proliferation after 2 weeks of supplementation (Chew et al. 1996).

IL-2 and IL-4 are cytokines which are both produced by activated T cells. While IL-2 production is concentrated among T-helper-1 cells, IL-4 is primarily produced by T-helper-2 cells (Mosmann \& Sad, 1996). IL-2 plays an important role in the proliferation of $\mathrm{T}$ cells following in vitro stimulation with $\mathrm{T}$-cell mitogens such as ConA. IL-4 has also been shown to stimulate T-cell proliferation. In the present study the low carotenoid intake resulted in a significantly reduced IL-2 secretion capacity. This reduction was paralleled by a suppressed proliferative response of these cells. According to these results carotenoids, or other substances provided by the consumption of carotenoidrich vegetables, may stimulate proliferation via their impact on IL-2 and/or IL-4 production. No other study looking at the effect of a high carotenoid intake through the consumption of vegetables on cytokine secretion has been published.

Several studies have investigated the effect of pure $\beta$-carotene on IL-2 production and on IL-2 receptor expression on activated lymphocytes in human subjects. Supplementation with $\beta$-carotene had no effect on IL-2 production in human subjects (Moriguchi et al. 1996; Santos et al. 1996) or in mice (Chew et al. 1996) and did not enhance IL2 receptor expression on PBMC (Daudu et al. 1994; Santos et al. 1996). Only in one study using four subjects did $\beta$-carotene supplementation result in enhanced IL-2 receptor expression on T lymphocytes (Watson et al. 1991). In in vitro studies with T-helper-1 and T-helper-2 clones, neither lycopene nor lutein affected the production of a T-helper-1 specific (interferon- $\gamma$ ) and of a T-helper-2 specific cytokine (IL-5) (Iyonouchi et al. 1996). Overall the majority of studies clearly show that pure carotenoids do not modulate T-cell cytokine production. This again suggests that probably other constituents in carotenoid-rich vegetables mediate the observed effects on $\mathrm{T}$ lymphocytes. In previous studies it has also been shown that $\beta$-carotene in vitro has no effect on interferon- $\gamma$ secretion, however, the secretion of monokines (IL-1, tumour necrosis factor $\alpha$ ) was significantly increased in vitro (Abdel-Fattah et al. 1993) and in vivo (Hughes et al. 1997a). 
One potential mechanism for an immunomodulatory effect of carotenoids is their ability to act as antioxidants and to quench singlet oxygen, which results in a lower generation of free radicals (Bendich, 1996). Free radicals are known to impair the integrity and functionality of membrane lipids and to affect signal transduction and gene expression in immune cells (Meydani et al. 1995b). Genotoxicity studies with PBMC from our study subjects revealed that there were fewer oxidized pyrimidine bases of the DNA after carrot juice consumption (Pool-Zobel et al. 1997) indicating antioxidative efficacy of carrot juice ingredients. However, the capacity of these PBMC to secrete IL-2 was not significantly different after carrot juice consumption compared with the end of the depletion period, which would not be in line with the proposed hypothesis. Furthermore, no close relationship was observed in vitro between the antioxidant activity of carotenoids and their modulating effect on T-helper cell functions (Iyonouchi et al. 1996).

The observed differences between the immunomodulatory potential of tomato juice, carrot juice, and spinach powder could be caused at least in part by the different quantities of vegetable products given to the study subjects. While tomato juice and carrot juice at a dose of $330 \mathrm{ml} / \mathrm{d}$ provided lycopene 28 -fold and $\beta$-carotene 10 -fold higher than the average intake in Germany, $10 \mathrm{~g} / \mathrm{d}$ spinach powder provided only five times the quantity of average lutein intake (Pelz et al. 1998). In addition, due to the design of our study without the use of wash-out periods, we do not know whether the treatments functioned independently, limiting the interpretation of our results. Because the treatment of the subjects was not randomized we do not know whether the two other vegetable products given after the depletion period would have induced the same results as were achieved with the tomato juice. In future studies the immunomodulatory activity of single vegetable products such as tomato juice should be investigated over a time range allowing the immunological effects to reach stability.

In conclusion, the results of the present study show that in healthy male adults the consumption of a low-carotenoid diet reduced T-lymphocyte functions. Tomato juice consumption restored these functions. During the intervention period the treatment with vegetable products never resulted in the stimulation of T-lymphocyte functions beyond baseline values, although the study subjects showed significantly elevated plasma carotenoid concentrations after the dietary intervention compared with baseline. The active constituents in tomato juice which mediate the immunomodulatory effects, as well as the biological significance of this, must be determined in further investigations.

\section{Acknowledgements}

The authors thank M. Falk, J. Theiss and T. Gadau for their excellent technical assistance and the volunteers from the Research Centre Karlsruhe for taking part in this study. We thank L. Korn for his statistical consultation. Tomato juice and carrot juice were provided by Schoenenberger Pflanzensäfte $\mathrm{GmbH}$, Magstadt, Germany, and spinach powder by Völpel, Königsmoos, Germany, which is gratefully acknowledged.

\section{References}

Abdel-Fattah G, Watzl B, Huang DS \& Watson RR (1993) Betacarotene in vitro stimulates tumor necrosis factor alpha and interleukin-1 alpha secretion by human peripheral blood mononuclear cells. Nutrition Research 13, 863-871.

Bendich A (1989) Carotenoids and the immune response. Journal of Nutrition 119, 112-115.

Bendich A (1991) Beta-carotene and the immune response. Proceedings of the Nutrition Society 50, 263-274.

Bendich A (1996) Antioxidant vitamins and human immune responses. Vitamins and Hormones 52, 35-62.

Block G, Patterson B \& Subar A (1992) Fruit, vegetables, and cancer prevention: a review of the epidemiological evidence. Nutrition and Cancer 18, 1-29.

Boeing H, Bohlscheid-Thomas S, Voss S, Schneeweiss S \& Wahrendorf J (1997) The relative validity of vitamin intakes derived from a food frequency questionnaire compared to 24hour recalls and biological measurements: results from the EPIC pilot study in Germany. European Prospective Investigation into Cancer and Nutrition. International Journal of Epidemiology 26, Suppl. 1, S82-S90.

Bone RA, Landrum JT, Friedes LM, Gomez CM, Kilburn MD, Menendez E, Vidal I \& Wang W (1997) Distribution of lutein and zeaxanthin stereoisomers in the human retina. Experimental Eye Research 64, 211-218.

Bundesinstitut für gesundheitlichen Verbraucherschutz and Veterinärmedizin (1994) German Food Code and Nutrition Data Base Version II.2. Berlin: Nutri-Science.

Burri BJ (1997) Beta-carotene and human health: a review of current research. Nutrition Research 17, 547-580.

Chew BP, Wong MW \& Wong TS (1996) Effects of lutein from marigold extract on immunity and growth of mammary tumors in mice. Anticancer Research 16, 3689-3694.

Clevidence BA, Khachik F, Brown ED, Nair PP, Wiley ER, Prior RL, Cao G, Morel DW, Stone W, Gross M \& Kramer T (1997) Human consumption of carotenoid-rich vegetables. In Antioxidant Methodology: in Vivo and in Vitro Concepts, pp. 53-62 [OI Aruoma and SL Cuppett, editors]. Champaign, IL: AOCS Press.

Daudu PA, Kelly DS, Taylor PC, Burri BJ \& Wu MM (1994) Effect of a low beta-carotene diet on the immune functions of adult women. American Journal of Clinical Nutrition 60, 969972.

Fotouhi N, Meydani M, Santos MS, Meydani SM, Hennekens CH \& Gaziano JM (1996) Carotenoid and tocopherol concentrations in plasma, peripheral blood mononuclear cells, and red blood cells after long-term $\beta$-carotene supplementation in men. American Journal of Clinical Nutrition 63, 553-558.

Gardner EM, Bernstein ED, Dorfman M, Abrutyn E \& Murasko DM (1997) The age-associated decline in immune function of healthy individuals is not related to changes in plasma concentrations of $\beta$-carotene, retinol, $\alpha$-tocopherol or zinc. Mechanisms of Aging and Development 94, 55-69.

Gerster H (1997) The potential role of lycopene for human health. Journal of the American College of Nutrition 16, 109-126.

Hughes DA, Wright AJA, Finglas PM, Peerless ACJ, Bailey AL, Astley SB, Pinder AC \& Southon S (1997a) The effect of betacarotene supplementation on the immune function of blood monocytes from healthy male nonsmokers. Journal of Laboratory and Clinical Medicine 129, 309-317.

Hughes DA, Wright AJA, Finglas PM, Peerless ACJ, Bailey AL, Astley SB, Pinder AC \& Southon S (1997b) Comparison of effects of beta-carotene and lycopene supplementation on the expression of functionally associated molecules on human monocytes. Biochemical Society Transactions 25, 206S.

Iyonouchi H, Sun S, Mizokami M \& Gross MD (1996) Effect of 
various carotenoids on cloned, effector-stage T-helper cell activity. Nutrition and Cancer 26, 313-324.

Kazi N, Radvany R, Oldham T, Keshavarzian A, Frommel TO, Libertin C \& Mobarhan S (1997) Immunomodulatory effect of beta-carotene on $\mathrm{T}$ lymphocyte subsets in patients with resected colonic polyps and cancer. Nutrition and Cancer 28, 140-145.

Key TJA, Thorogood M, Appleby PN \& Burr ML (1996) Dietary habits and mortality in 11000 vegetarians and health conscious people: results of a 17 year follow up. British Medical Journal 313, 775-779.

Kramer TR \& Burri BJ (1997) Modulated mitogenic proliferative responsiveness of lymphocytes in whole-blood cultures after a low-carotene diet and mixed-carotenoid supplementation in women. American Journal of Clinical Nutrition 65, 871-875.

Mangels AR, Holden JM, Beecher GR, Forman MR \& Lanza E (1993) Carotenoid content of fruits and vegetables: an evaluation of analytic data. Journal of the American Dietetic Association 93, 284-296.

Mayne ST (1996) Beta-carotene, carotenoids, and disease prevention in humans. FASEB Journal 10, 690-701.

Meydani SN, Santos MS, Ribaya-Mercado JD, Leka L, Han SN \& Russell RM (1995a) Effect of $\beta$-carotene on the immune response of elderly women. FASEB Journal 9, A170 Abstr.

Meydani SN, Wu D, Santos MS \& Hayek MG (1995b) Antioxidants and immune response in aged persons: overview of present evidence. American Journal of Clinical Nutrition 62 , 1462S-1476S.

Moriguchi S, Okishima N, Sumida S, Okamura K, Tatsuya D \& Kishino Y (1996) Beta-carotene supplementation enhances lymphocyte proliferation with mitogens in human peripheral blood lymphocytes. Nutrition Research 16, 211-218.

Mosmann TR \& Sad S (1996) The expanding universe of T-cell subsets: Th1, Th2 and more. Immunology Today 17, 138-146.

Müller H, Bub A, Watzl B \& Rechkemmer G (1999) Plasma concentrations of carotenoids in healthy volunteers after intervention with carotenoid-rich foods. European Journal of Nutrition 38, 35-44.
Ness AR \& Powles JW (1997) Fruit and vegetables, and cardiovascular disease: a review. International Journal of Epidemiology 26, 1-13.

Omenn GS, Goodman GE, Thornquist MD, Balmes J, Cullen MR, Glass A, Keogh JP, Meyskens F, Valaris B, Williams JH, Barnhart S \& Hammer S (1996) Effects of a combination of beta-carotene and vitamin A on lung cancer and cardiovascular disease. New England Journal of Medicine 334, 1150-1155.

Pelz R, Schmidt-Faber B \& Heseker H (1998) Die Carotinoidzufuhr in der Nationalen Verzehrsstudie (Carotenoid intake in the German National Food Consumption Survey). Zeitschrift für Ernährungswissenschaft 37, 319-327.

Pool-Zobel BL, Bub A, Müller H, Wollowski I \& Rechkemmer G (1997) Consumption of vegetables reduces genetic damage in humans: first results of a human intervention trial with carotenoid-rich foods. Carcinogenesis 18, 1847-1850.

Ringer TV, DeLoof MJ, Winterrowd GE, Francom SF, Gaylor SK, Ryan JA, Sanders ME \& Hughes GS (1991) Beta-carotene's effects on serum lipoproteins and immunologic indices in humans. American Journal of Clinical Nutrition 53, 688-694.

Santos MS, Meydani SN, Leka L, Wu D, Fotouhi N, Meydani M, Hennekens CH \& Gaziano JM (1996) Natural killer cell activity in elderly men is enhanced by beta-carotene supplementation. American Journal of Clinical Nutrition 64, 772-777.

Stahl W \& Sies H (1996) Lycopene: a biologically important carotenoid for humans? Archives of Biochemistry and Biophysics 336, 1-9.

Steinmetz KA \& Potter JD (1991) Vegetables, fruit, and cancer: II. Mechanisms. Cancer Causes and Control 2, 427-442.

The Alpha-Tocopherol, Beta-Carotene Cancer Prevention Study Group (1994) The effect of vitamin E and beta carotene on the incidence of lung cancer and other cancers in male smokers. New England Journal of Medicine 330, 1029-1035.

Watson RR, Prabhala RH, Plezia PM \& Alberts DS (1991) Effects of beta-carotene on lymphocyte subpopulations in elderly humans: evidence for dose-response relationship. American Journal of Clinical Nutrition 53, 90-94. 